\title{
High vacuum tribology of polycrystalline diamond coatings
}

\author{
AWADESH K MALLIK $^{1, *}, \mathrm{~S}^{\text {A SHIVASHANKAR }}{ }^{1}$ and \\ S K BISWAS ${ }^{1,2}$ \\ ${ }^{1}$ Materials Research Centre, Indian Institute of Science, Bangalore 560012 \\ ${ }^{2}$ Department of Mechanical Engineering, Indian Institute of Science, \\ Bangalore 560012 \\ *Corresponding author, address: Central Glass and Ceramic Research Institute \\ CSIR India, 196, Raja S. C. Mullick Road, Kolkata 700032 \\ e-mail: amallik@cgcri.res.in
}

MS received 20 September 2008; revised 27 November 2008

\begin{abstract}
Polycrystalline diamond coatings have been grown on unpolished side of $\mathrm{Si}(100)$ wafers by hot filament chemical vapour deposition process. The morphology of the grown coatings has been varied from cauliflower morphology to faceted morphology by manipulation of the growth temperature from $700^{\circ} \mathrm{C}$ to $900^{\circ} \mathrm{C}$ and methane gas concentration from $3 \%$ to $1.5 \%$. It is found that the coefficient of friction of the coatings under high vacuum of $133.32 \times 10^{-7} \mathrm{~Pa}\left(10^{-7}\right.$ torr $)$ with nanocrystalline grains can be manipulated to 0.35 to enhance tribological behaviour of bare Si substrates.
\end{abstract}

Keywords. Polycrystalline diamond coatings; hot filament CVD; high vacuum tribology.

\section{Introduction}

India has its about four decades-old own space program and there is a recent enhanced interest in space research among Indian scientist with successful launch of chandrayaan-1 and with forthcoming human exploration to moon. Satellites will be put into orbit with solar cell panels which need to be open and close. Spacecraft will be launched with or without man. All these structures will have articulating mechanical assemblies, such as doors, panels, etc. which need to be lubricated for proper functioning. There is an emerging area of space tribology where liquid lubricant with vapour pressure can not be used under vacuum; henceforth solid lubricant will find its application in space or ultra high vacuum environment.

Among all the solid lubricants, diamond has the least value for coefficient of friction as low as 0.001 under water, 0.05 to 0.15 in air and 0.5 to 1 under vacuum (Tzeng 1993), and it does not wear because of highest hardness.

Usefulness of polycrystalline diamond (PCD) coated machine elements operating in the continuum-mechanical regime of industrial applications (micrometers to centimeters and

*For correspondence 
second to years in the space-time continuum) is governed by microscopic features of the counterfaces. The interaction is heavily influenced by the temperature and the atmosphere of operation, as well as structure and purity of the PCD coatings. Coating surfaces with PCD offers exciting possibilities of substantially reducing the wear and possibly the friction of the critical moving mechanical assemblies.

There are several mechanisms of friction proposed by different authors for diamond films. Gardos $(1994,1999)$ through his research over decades has proposed that the real area of contact is very much less than the apparent area of contact and the local stress is so great at these points that severe plastic deformation and possibly cracking occur. The tip of each asperity is flattened by crushing and shearing to produce a small plane or almost planar regions. Over the small, flattened regions intimate atomic contact between the two surfaces occur. Computer modelling of hydrogenated PCD vs. PCD tribocontact gives a value of $0 \cdot 132$ for coefficient of kinetic friction.

Desorption of hydrogen or other adsorbates in high vacuum create dangling bonds on the surface of diamond. If these unpaired electrons interacted immediately with a similarly activated counterface to attempt chemical bonding, high friction forces would be generated. If the hydrogen that screens or saturates the singly occupied carbon orbitals on the surface is replaced by other gases (for example fluorine or oxygen), coefficient of kinetic friction would still be relatively low (Gardos 1999), Feng et al (1992). Its actual magnitude would depend on the interfacial affinity of the substrates adsorbed species for the counterface exhibiting its own particular surface chemistry. Table 1 shows the coefficient of friction (COF) values of PCD reported by various authors (Gardos 1999, Feng et al 1992, Avigal et al 1997, Miyoshi et al 1993, Bharat Bhushan et al 1993).

Several facets are observed when diamond films are produced by chemical vapour deposition. Martin \& Judith (1995) have used molecular dynamic simulations to examine the friction which occurs when the (100) reconstructed surfaces of two diamond lattices are placed in sliding contact. They found that the general dependence of coefficient of friction on applied load is similar, regardless of the facet. It was supported by AFM experiments by Geoffrey et al (1993) on coefficient of friction between diamond (100) and (111) surfaces. Molecular dynamic simulations by Martin \& Judith (1997) of entrapped hydrocarbons (third body) between hydrogen terminated (111) faces show that the size and shape of the molecules entrapped and alignment of opposite faces are very important to determine coefficient of friction.

Friction and wear behaviour of PCD coatings are well documented in the literature. The reported results are for vacuum level of $133.32 \times 10^{-5} \mathrm{~Pa}\left(10^{-5}\right.$ torr $)$ or ultra high vacuum of $133.32 \times 10^{-9} \mathrm{~Pa}\left(10^{-9}\right.$ torr). Generally, $\mathrm{PCD}$ is grown on the polished side of bare $\mathrm{Si}$ wafers to enhance the tribological properties. Here we have reported at vacuum level of $133.32 \times 10^{-7} \mathrm{~Pa}\left(10^{-7}\right.$ torr) for which there is no published data available. Moreover, we have grown PCD coatings on the unpolished side of Si wafers, over $20 \times 20 \mathrm{~mm}^{2}$ surface area suitable to perform vacuum pin on disc experiments. There is no available literature about the friction behaviour of PCD grown on the unpolished surface of $\operatorname{Si}(100)$ wafers. Here we will show manipulation of PCD coating morphology by varying hot filament CVD process parameters and its effect on tribological behaviour under high vacuum.

\section{Materials and methods}

A conventional Hot Filament Chemical Vapour Deposition (HFCVD) reactor (described by Mallik et al submitted) was used to deposit diamond on silicon substrates. The detailed 


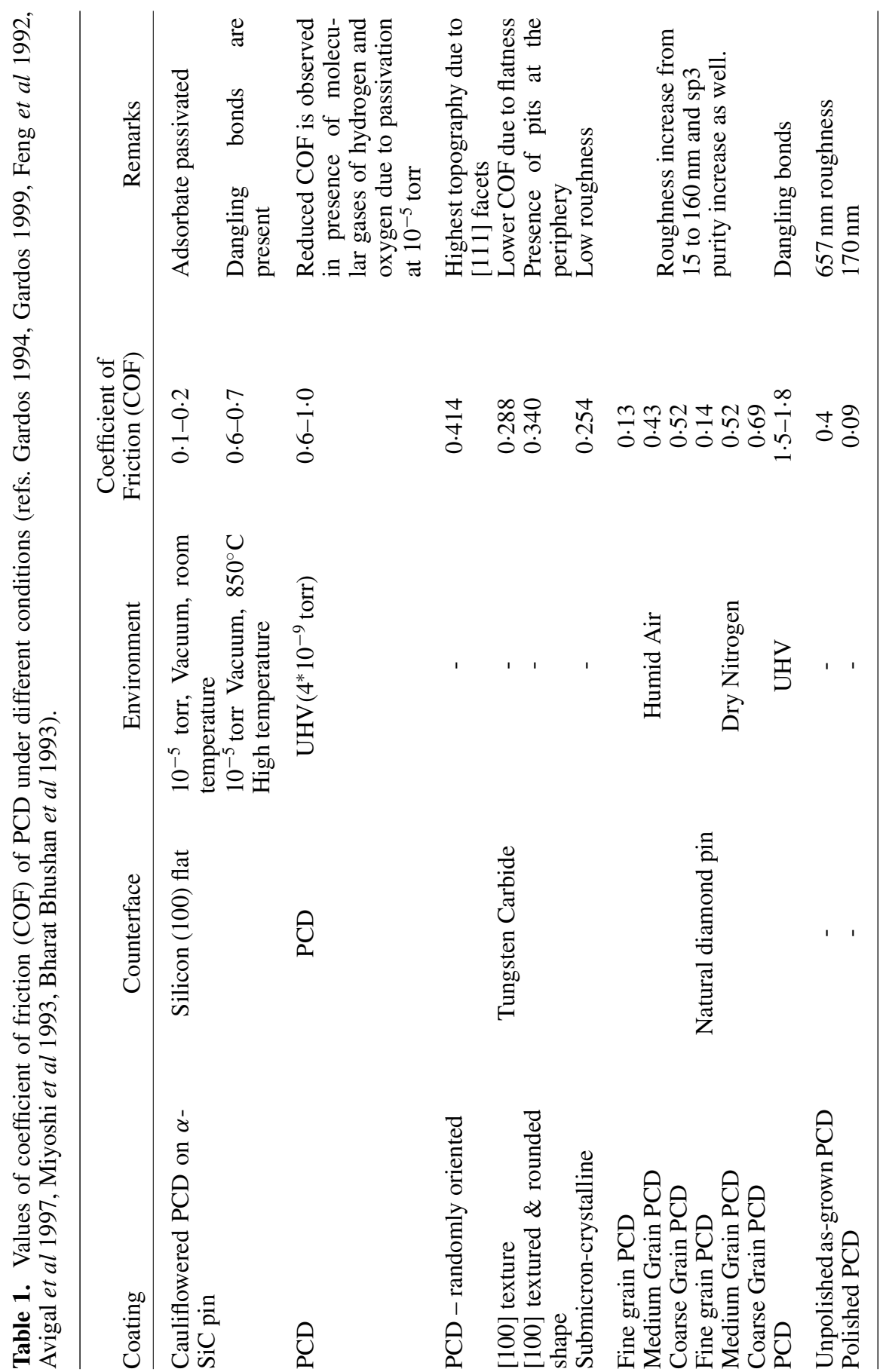


experimental procedures can be found in authors' previous communication (Mallik et al submitted). The reactor was purged with hydrogen gas before and after each run. Following are the process parameters used: (i) Substrate: Unpolished side of Si (100) wafer, ultrasonically scratched using diamond paste. (ii) Precursor Gas: Mixture of methane and hydrogen ( $1 \%$ to $3 \% \mathrm{CH}_{4}$ by volume) (iii) Substrate temperature: $700^{\circ}-900^{\circ} \mathrm{C}$. (iv) Filament temperature: $2000^{\circ} \mathrm{C}$, measured by two wavelength optical pyrometer (MIKRON). (v) Filament to substrate distance: $5 \mathrm{~mm}$. (vi) Base pressure: $5 \mathrm{~Pa}\left(50 \times 10^{-3} \mathrm{mbar}\right)$. (vii) Process pressure: 3333.05 Pa (25 torr).

We have varied the methane concentration and substrate temperature to manipulate the PCD morphology. The substrate temperature was controlled using a thermocouple and a feed back temperature-controller. Gas flow rate was controlled using mass flow controllers (Bronkhorst Hi-Tec, EL-Flow). Raman spectroscopy was done to monitor the quality of the deposit. The Raman experiments were performed in a $90^{\circ}$ geometry using a Jobin Yvon Triax 550 tripple grating spectrometer equipped with cryogenic charge-coupled device camera, using diode - pumped frequency doubled solid state Nd-YAG laser of $532 \mathrm{~nm}$ (Model DPSS 532-400, Coherent Inc.). A super notch filter was used to eliminate the Rayleigh scattering. The deposited specimen was broken, polished and the cross section viewed in the Scanning Electron Microscope to measure the film thickness. As grown morphology and wear track were also viewed under scanning electron microscope. A profilometer (Taylor and Hobson, Talysurf) was used to measure the roughness of the surface, here we report the centre line average (CLA). The grain size of the deposited film was measured using an AFM (Explorer ${ }^{\mathrm{TM}}$, Veeco Instruments Inc.) in the contact mode.

One pin-on-disc tribometer was used to measure the coefficient of friction of polycrystalline diamond coatings. Figure 1 shows the schematic high vacuum pin-on-disc configuration. An arm carries strain gauge force transducer. The deflection of the arm gives the friction force. The arm carries a (SS440C) steel ball rider of $4 \mathrm{~mm}$ diameter. The pin is coaxially loaded by

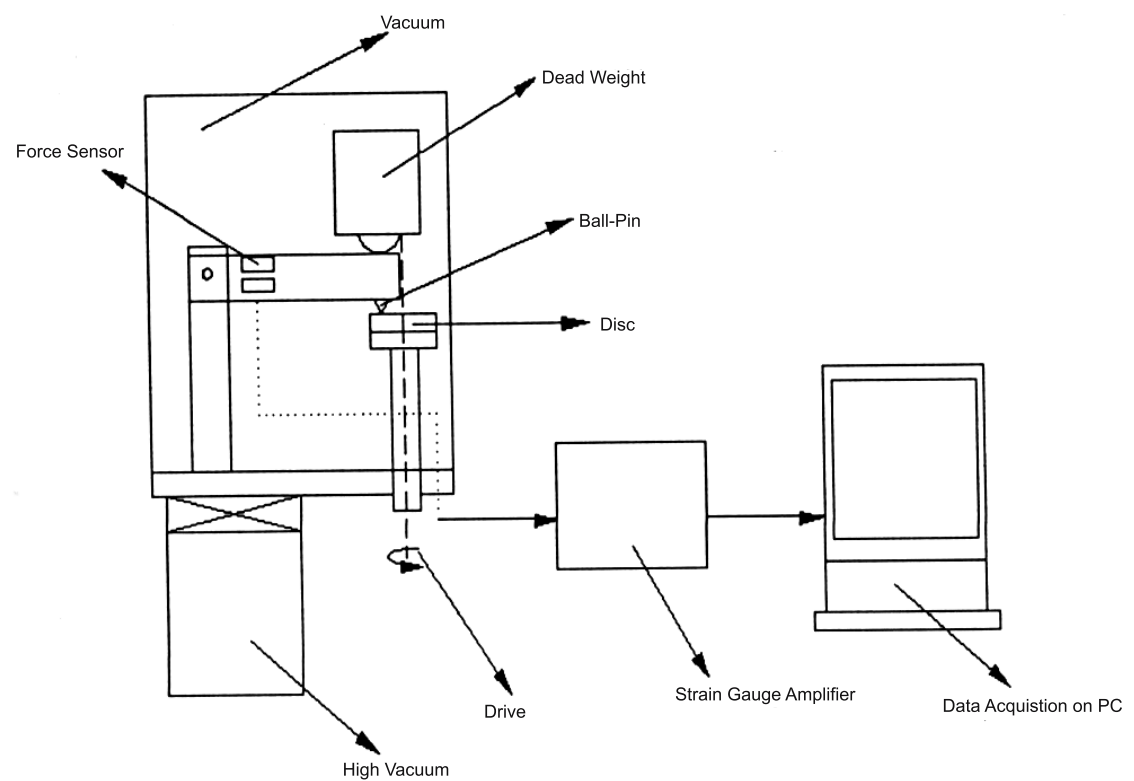

Figure 1. Schematic of vacuum pin-on-disc. 

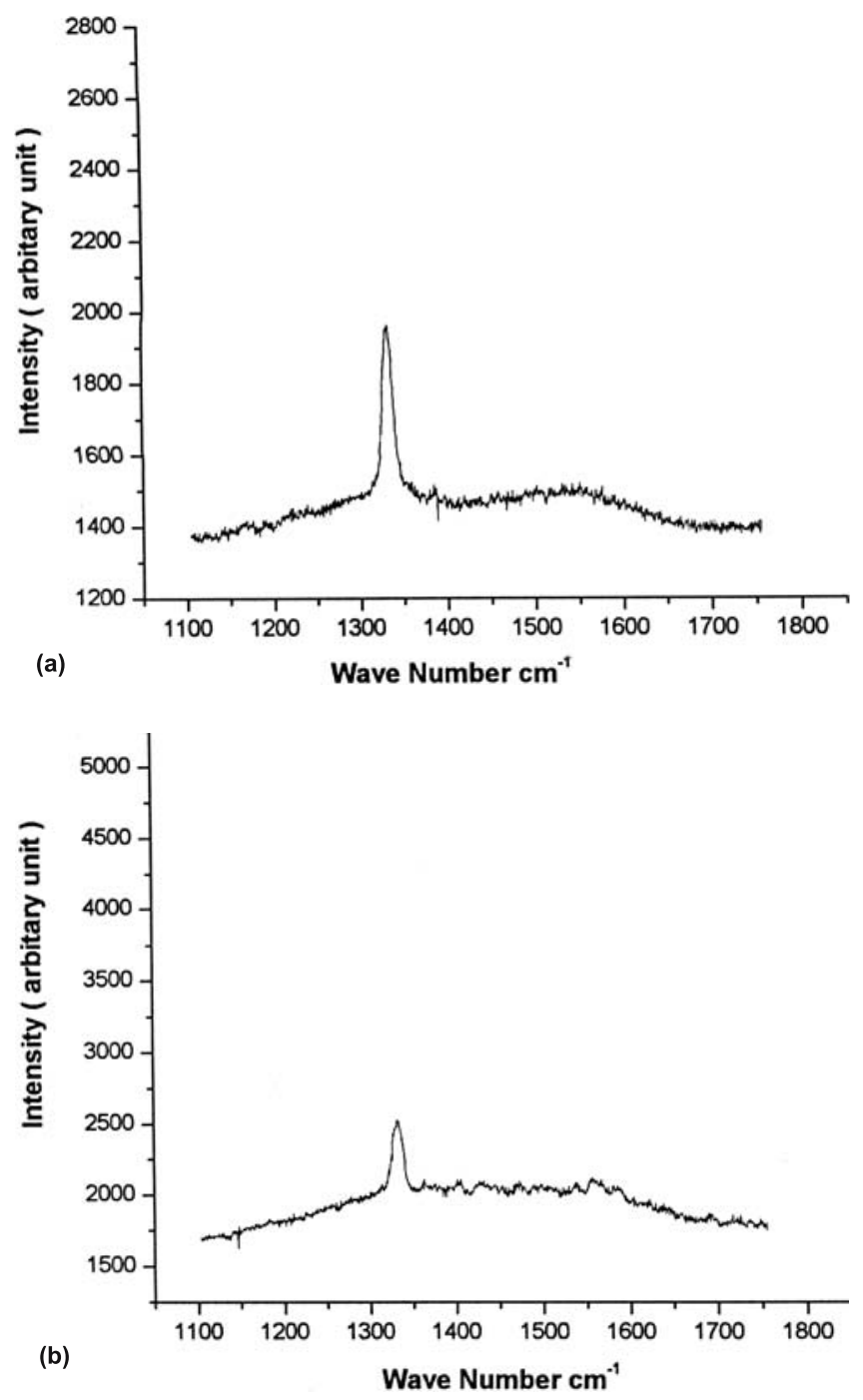

Figure 2. Raman spectra of PCD coatings grown at (a) $1.5 \% \mathrm{CH}_{4}$ and $900^{\circ} \mathrm{C}$ substrate temperature, (b) $3 \% \mathrm{CH}_{4}$ and $800^{\circ} \mathrm{C}$ substrate temperature.

dead weight. The weight used in all experiments was $1 \mathrm{~N}$. The pin presses on the disc which rotates at $0 \cdot 1-0 \cdot 15 \mathrm{~m} / \mathrm{sec}$ by a drive which is placed outside the vacuum system. The whole assembly is placed inside a vacuum which is evacuated to $133.32 \times 10^{-7} \mathrm{~Pa}\left(10^{-7}\right.$ torr $)$. The experiments were done for $0.5277 \mathrm{~km}$. The disc is a $20 \times 20 \mathrm{~mm}^{2}$ Silicon (100) wafer bare or coated with PCD on its unpolished side. The coated discs were wrapped in tissue paper and were stored in ordinary sample boxes before carrying out tribological experiments.

\section{Results and discussions}

The Raman spectrum in figure 2 a shows one peak at $1332 \mathrm{~cm}^{-1}$ from the coatings grown with $1.5 \% \mathrm{CH}_{4}$ and $900^{\circ} \mathrm{C}$ substrate temperature and Raman spectrum of figure $2 \mathrm{~b}$ shows one peak at $1332 \mathrm{~cm}^{-1}$ from coatings grown at higher methane concentration of $3 \%$ and lower substrate 
temperature of $800^{\circ} \mathrm{C}$. The peak at $1332 \mathrm{~cm}^{-1}$ is characteristic of $\mathrm{C}$ tetrahedral whereas the hump at $1500-1600 \mathrm{~cm}^{-1}$ is a characteristic of graphite. We mark the (diamond peak) coating quality by the ratio of the intensity of the peak to hump, the higher the $1332 \mathrm{~cm}^{-1}$ peak and lower the $1500-1600 \mathrm{~cm}^{-1}$ hump intensity we infer an enhancement of coating quality. Now, if we compare two peaks of $2 \mathrm{a}$ and $2 \mathrm{~b}$, we will find that figure $2 \mathrm{a}$ has more intense signal from $\mathrm{sp} 3$ carbon structure in the coating than figure $2 \mathrm{~b}$. Moreover, there is little hump in between $1500-1600 \mathrm{~cm}^{-1}$ in both the raman spectrograph typical of graphitic and amorphous diamond in the structure. Thus, both the films are pure diamond films with few graphitic inclusions but the figure 2a has more intense signal from sp3 structure indicating higher purity of the coating. The surface morphologies of the same coatings can be seen in figures $3 \mathrm{c}$ and $3 \mathrm{~d}$ respectively.

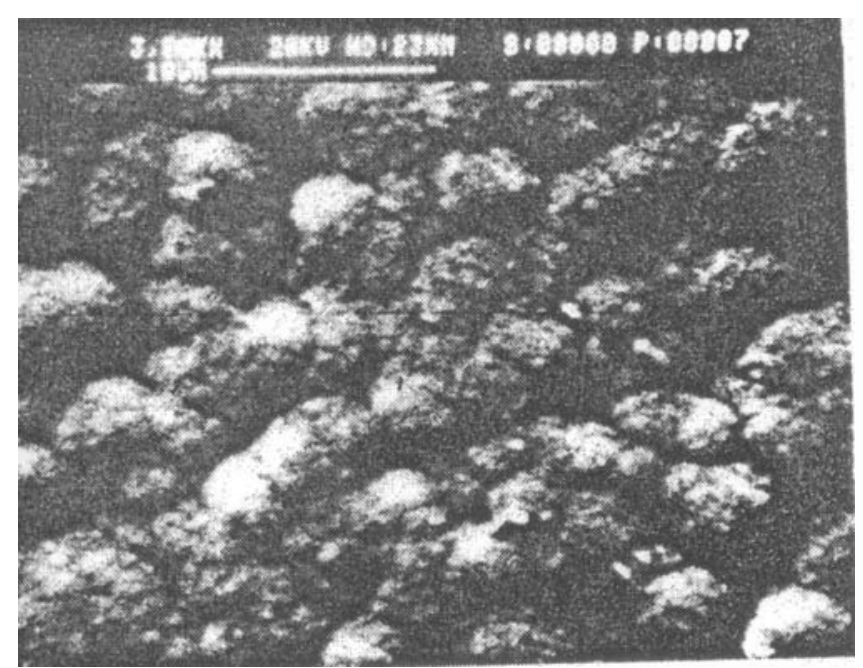

(a)

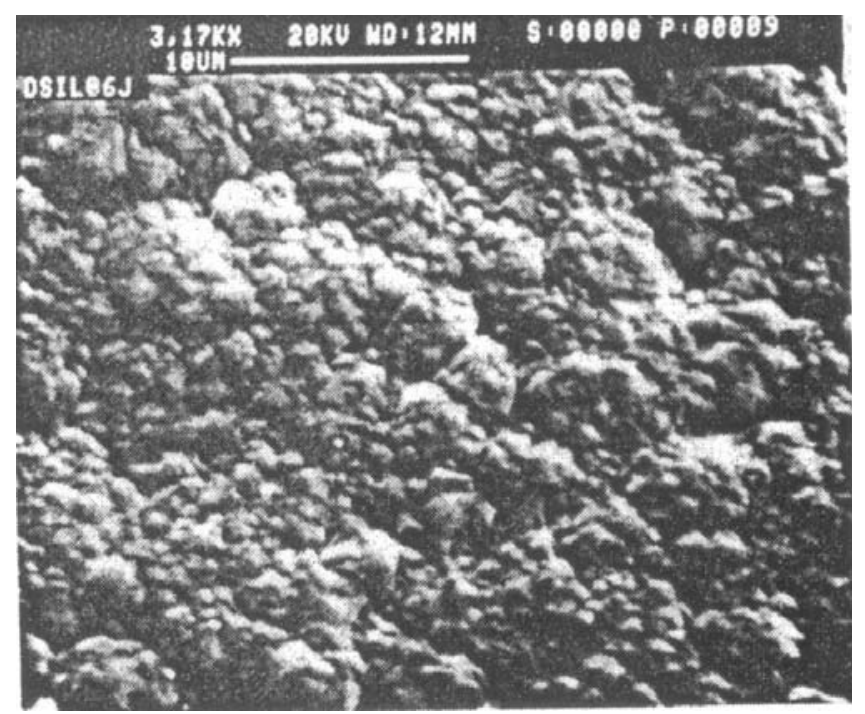

(b)
Figure 3. Continued. 


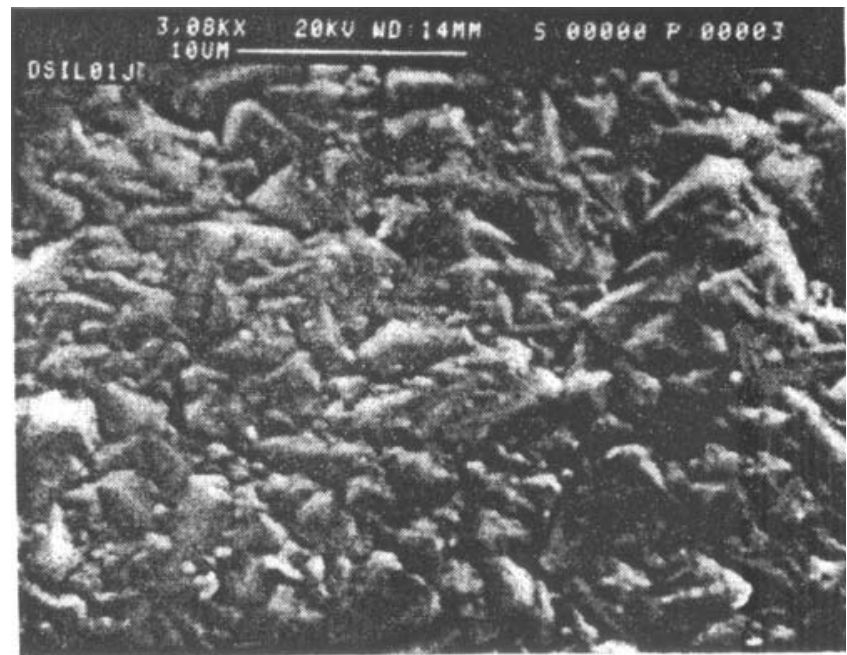

(c)

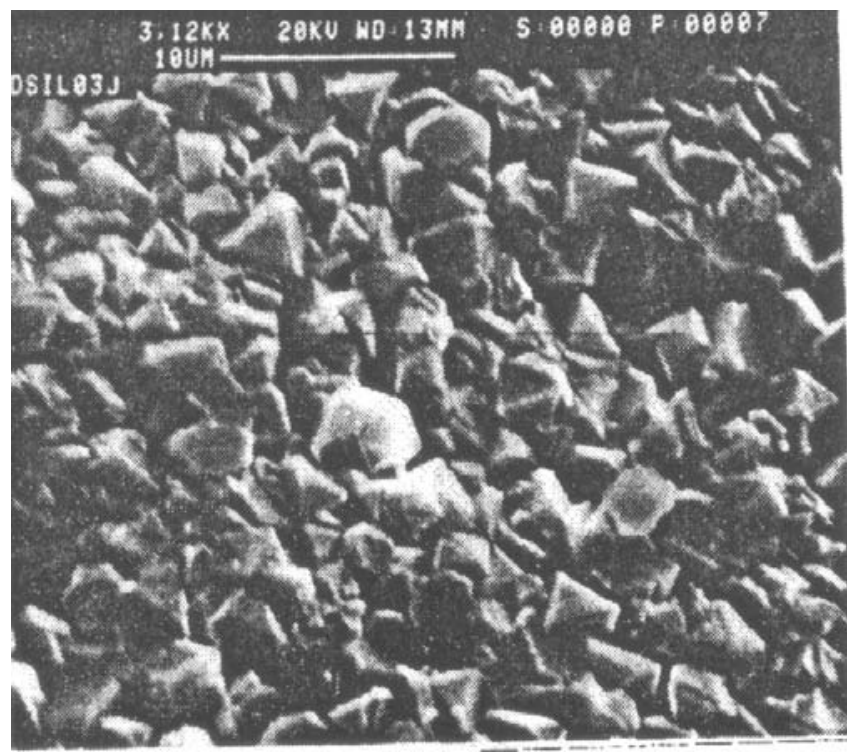

(d)
Figure 3. SEM micrograph of PCD coatings grown with $3 \% \mathrm{CH}_{4}$ at substrate temperature of (a) $700^{\circ} \mathrm{C}$; (b) $750^{\circ} \mathrm{C}$; (c) $800^{\circ} \mathrm{C}$ and (d) $900^{\circ} \mathrm{C}$ with $1.5 \%$ methane.

It is evident that coatings with higher purity have faceted morphology and coatings with less purity have less faceted and more nanocrystalline features.

The grains are found to be 3-5 microns for faceted morphology and cauliflower morphology has 100-200 nm size nanocrystalline grains, as measured with AFM in contact mode. It is clear that low methane concentration and high substrate temperature yield a faceted structure while lower substrate temperature and higher methane concentration yield a more spherical cauliflower structure (Mallik et al submitted) with nanocrystallie grains. This trend has been shown in figure 3 with gradual variation of the process parameters there is gradual change in morphology. The roughness of the film also increases systematically as the morphology 
Table 2. Change of morphology with variation in methane concentration and substrate temperature.

\begin{tabular}{cccc}
\hline $\mathrm{CH}_{4}(\%)$ & $\begin{array}{c}\text { Substrate } \\
\text { Temperature }\left({ }^{\circ} \mathrm{C}\right)\end{array}$ & $\begin{array}{c}\text { Morphology } \\
\text { Morphology }\end{array}$ & $\begin{array}{c}\text { Profilometer Average } \\
\text { Roughness }(\mathrm{Ra}, \mu \mathrm{m})\end{array}$ \\
\hline 3 & 800 & $\begin{array}{c}\text { Cauliflower } \\
\text { Mixture of Cauliflower } \\
\text { and Faceted }\end{array}$ & 0.19 \\
& 900 & Faceted & 0.31 \\
1.5 & 900 & & 0.53 \\
\hline
\end{tabular}

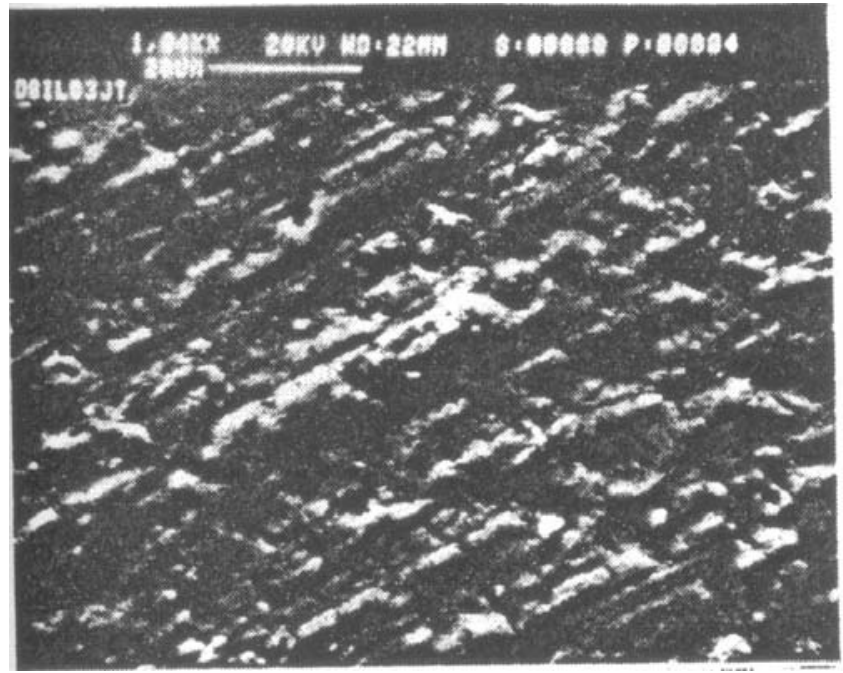

Figure 4. Wear track in faceted coatings.

changes from cauliflower to faceted due to increase in substrate temperature (table 2). Figure 4 shows an abraded track of a PCD coating.

Figure 5 shows the friction recording. Table 3 summarizes the change in (steady state) coefficient of friction due to changes in substrate temperature. The average coefficient of friction follows the trend in roughness, lower the temperature lower is the average coefficient of friction. Table 4 gives the change in average coefficient of friction due to change in methane concentration. It is seen that the methane concentration in this range (1.5-3\%) does not have a profound effect on the average coefficient of friction values although there is a trend for

Table 3. Effect of morphology on average coefficient of friction at constant $\mathrm{CH}_{4} 3 \mathrm{vol} \%$ with variation in substrate temperature.

\begin{tabular}{lccc}
\hline $\begin{array}{l}\text { Substrate } \\
\text { temperature }\left({ }^{\circ} \mathrm{C}\right)\end{array}$ & $\begin{array}{c}\text { Morphology } \\
\text { (figure 3) }\end{array}$ & $\begin{array}{c}\text { Avg. Roughness } \\
(\mu \mathrm{m})\end{array}$ & $\begin{array}{c}\text { Average Coefficient of friction } \\
\text { with standard deviation }\end{array}$ \\
\hline 700 & Pure cauliflower & 0.07 & $0.35 \pm 0.01$ \\
750 & Less Cauliflower & $0 \cdot 11$ & $0.38 \pm 0.01$ \\
800 & More faceted & $0 \cdot 19$ & $0.43 \pm 0.01$ \\
900 & Pure faceted & 0.31 & $0.45 \pm 0.01$ \\
\hline
\end{tabular}


Table 4. Effect of morphology on coefficient of friction at constant substrate temperature with variation in $\mathrm{CH}_{4}$ vol\%.

\begin{tabular}{llc}
\hline $\begin{array}{l}\text { Substrate } \\
\text { temperature }\left({ }^{\circ} \mathrm{C}\right)\end{array}$ & $\begin{array}{c}\mathrm{CH}_{4} \\
\text { vol\% }\end{array}$ & $\begin{array}{c}\text { Average coefficient of friction } \\
\text { with standard deviation }\end{array}$ \\
\hline 800 & 1.5 & $0.49 * \pm 0.01$ \\
800 & 2 & $0.46 \pm 0.01$ \\
800 & 3 & $0.43 \pm 0.01$ \\
900 & 1.5 & $0.49 * \pm 0.01$ \\
900 & 3 & $0.45 \pm 0.01$
\end{tabular}

*Wear track was visible as shown in figure 4

the friction to reduce slightly with increasing methane concentration. Reported coefficient of friction values are average of at least 5 number of experiments.

Our results are in agreement with those reported by Miyoshi et al (1993). They have reported a decrease in coefficient of friction with a decrease in grain size. Figure 3 clearly depicts the fact that the grain size varies from few hundred nanometers in cauliflower morphology to few microns in faceted morphology. We report this increases in the friction. We surmise from the results presented that this happens because the roughness of the film increases as it becomes more faceted. Although the evidence is not conclusive, we may suggest that a rough diamond surface abrading the steel ball would yield higher friction than when a smooth diamond surface abrades the steel ball. If we consider the PCD surface as hilly terrain with asperities and valleys, faceted morphology has deeper and steeper obstacles to overcome, whereas nanocrystalline grains with cauliflower morphology has shallow valleys and rounded asperities, thus less resistence it provides to the sliding counterface. It is also possible that large grains embedded in diamond would offer higher resistance to sliding motion when interacted with the diamond disc.

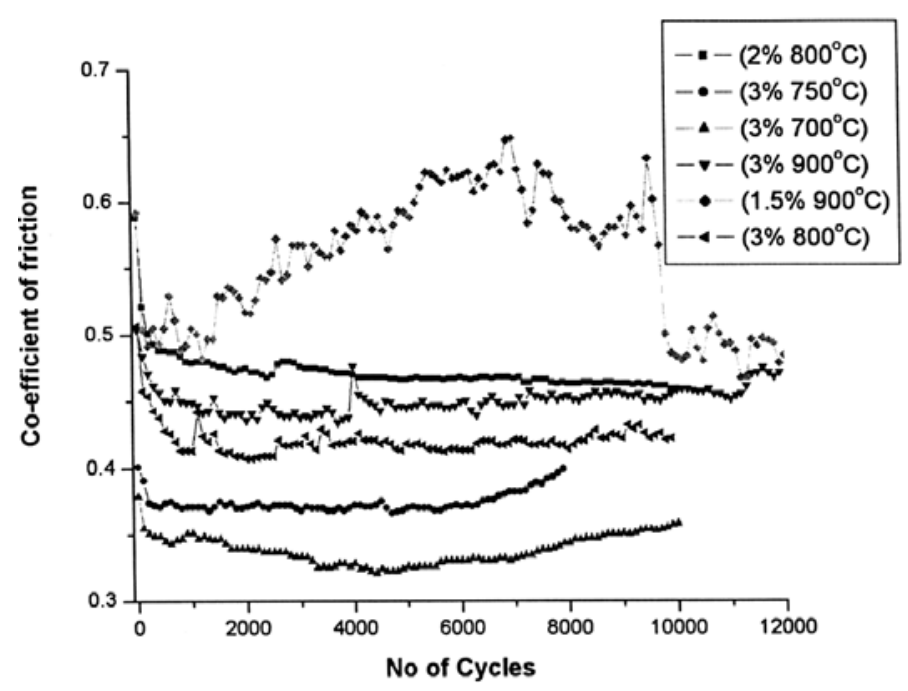

Figure 5. Friction curves of polycrystalline diamond coatings under high vacuum, grown with variation in $\mathrm{CH}_{4}(\%)$ and substrate temperature $\left({ }^{\circ} \mathrm{C}\right)$ when other parameters are constant (each friction curve is for coating grown at specified conditions). 


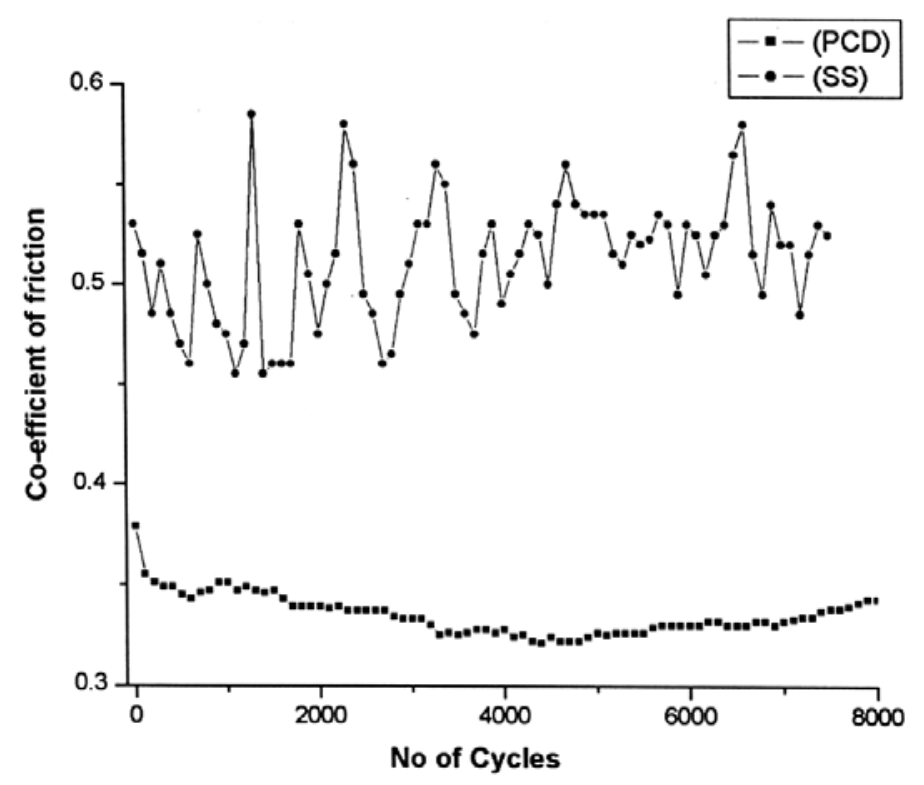

Figure 6. Friction curves for bare Silicon Substrates (SS) and polycrystalline diamond-coated Silicon Substrates (PCD).

While the trend in friction observed here is in agreement with that of Miyoshi et al (1993), we would like to note that they had achieved a friction coefficient of 1.5-1.8 when sliding a diamond coating of 3.3 micron grain size in $133.32 \times 10^{-9} \mathrm{~Pa}\left(10^{-9}\right.$ torr $)$ vacuum. In our experiments the highest value of coefficient of friction obtained was 0.53 under $133.32 \times$ $10^{-7} \mathrm{~Pa}\left(10^{-7}\right.$ torr $)$ vacuum with $3-5$ micron faceted grains.

We would like to observe that according to friction curve in figure 6 , bare silicon wafer on the polished surface has coefficient of friction in the order of $0 \cdot 5$, whereas when coated on the back side of the same wafers with PCD coatings under same tribological condition it is decreased to 0.35 by a suitable manipulation of the diamond film morphology. Depositing PCD on the unpolished side is somewhat counter-intuitive for tribological applications, since it would have higher roughness values in the order of one micron. But the substrate roughness (Mallik et al submitted) plays an important role in diamond growth behaviour. Surface energy plays a major contribution for PCD nucleation and growth. Substrates on the backside with higher roughness provide sufficient surface energy, necessary for growth and nucleation kinetics. Moreover, it provides more hiding space for diamond particles of diamond paste used for ultrasonic scratching prior to deposition in order to enhance diamond nuleation. So it is easy to grow diamond at the backside of Si wafer because of (i) enough surface energy due to inherent roughness, (ii) more hiding space for diamond seeds. With so much of favourable conditions diamond coatings with nanocrystalline grains when deposited reduce the roughness of the backside of wafer from $0.98 \mu \mathrm{m}$ to $0.07 \mu \mathrm{m}$ and thereby enhance the tribological behaviour of the bare Si wafers.

The coatings were wrapped in a tissue paper and stored in ordinary sample boxes prior to carrying out tribological experiments. The HFCVD reactor was purged with hydrogen before and after deposition, therefore it can be assumed that the surface of PCD is stabilized by none other than hydrogen. This hydrogen stabilized surface when exposed to vacuum, it loses surface hydrogen and left with dangling bonds (well-established fact in the literature), 
which interacts with steel ball under $133 \cdot 32 \times 10^{-7} \mathrm{~Pa}\left(10^{-7}\right.$ torr $)$. When the steel ball travels through hilly terrain of PCD surface, it is the roughness (sharpness of asperity angle and depth of valley) determines the coefficient of friction values.

\section{Conclusions}

Polycrystalline diamond coatings when grown on the unpolished side of the $\mathrm{Si}(100)$ wafer by hot filament CVD, better coefficient of friction values under vacuum (as good as in humid environment or dry nitrogen environment (Miyoshi et al 1993)) is obtained in comparison to the literature values due to manipulated morphology. Coefficient of friction under vacuum of $133.32 \times 10^{-7} \mathrm{~Pa}\left(10^{-7}\right.$ torr $)$ has found to be manipulated to 0.35 to enhance tribological behaviour of $\mathrm{Si}(100)$ wafers.

Authors would like to thank Mr. H S Shamsundar for helping in scanning electron microscopy and profilometer studies. Mr. Nagabhushanam Indian Space Application Centre (ISAC), Bangalore has provided us with the wear \& friction data. Dr. N Chandrabhas has allowed accessing Raman Spectrometer at Jawaharlal Nehru Centre for Advanced Scientific Research (JNCASR), Bangalore. Md. Motin Sheikh has carried out the Raman spectrum measurements. The authors thank Indian Space Research Organisation for financial support and the Ceramic Technological Institute (CTI), Bharat Heavy Electrical Ltd. (BHEL) for making available deposition facilities.

\section{References}

Avigal Y, Glozman O, Etsion I, Halperin G, Hoffman A 1997 [100]-Textured diamond films for tribological applications. Diamond and Related Mat. 6(2-4): 381-385

Bharat Bhushan, Vish V Subramaniam, Ajay Malshe, Gupta B K, Juai Ruan 1993 Tribological properties of polished diamond films. J. Appl. Phys. 74(6): 4174

Feng Z, Tzeng Y, Field J E 1992 Friction of diamond on diamond in ultra-high vacuum and lowpressure environments. Phys. D: Appl. Phys. 25(10) 1418-1424

Gardos M N 1994 Synthetic Diamond: Emerging CVD Science and Technology, Chapter 12, Tribology and Wear Behaviour of Diamond, Wiley-Interscience

Gardos M N 1999 Tribological fundamentals of polycrystalline diamond films. Surface and Coatings Technology 113(3): 183-200

Geoffrey J Germann, Sidney R Cohen, Gabi Neubauer, Gary M McClelland, Hajime Seki, Coulman D 1993 Atomic scale friction of a diamond tip on diamond (100) and (111) surfaces. J. Appl. Phys. 73(1): $163-167$

Mallik Awadesh K, Binu S R, Satapathy L N, Chandrabhas Narayana, Md. Motin Seikh, Biswas S K Effect of substrate roughness on growth of diamond by hot filament CVD. Bull. Mat. Sci. (submitted)

Martin D Perry, Judith A Harrison 1995 Universal aspects of the atomic-scale friction of diamond surfaces. J. Phys. Chem. 99(24): 9960-9965

Martin D Perry, Judith A Harrison 1997 Friction between diamond surfaces in the presence of small third-body molecules. J. Phys. Chem. B101(8): 1364-1373

Miyoshi Kazuhisa, Richard L C Wu, Alan Garscadden, Paul N Barnes, Howard E Jackson 1993 Friction and wear of Plasma deposited diamond films. J. Appl. Phys. 74(7): 4446

Takeno T, Komoriya T, Nakamori I, Miki H, Abe T, Uchimoto T, Takagi T 2005 Tribological properties of partly polished diamond coatings. Diamond and Related Materials 14(11-12): 2118-2121

Tzeng Y 1993 Very low friction for diamond sliding on diamond in water. Appl. Phys. Lett. 63(26): 